\title{
A relação com o aprender na universidade e o meio ambiente de estudos
}

\author{
Saeed Paivandi \\ Université de Lorraine | Nancy | França
}

\section{Resumo}

Examina-se a ligação entre avaliação subjetiva do contexto de estudos realizados pelos estudantes em relação com o aprender na Universidade. Essa análise baseia-se em uma enquete qualitativa, realizada entre 2005 e 2008, com estudantes de Letras, Ciências Humanas e Ciências Sociais em cinco universidades parisienses. A investigação revelou a lógica aprendendo-aprender e sua reflexividade no percurso e dinâmicas que dão sentido às trajetórias individuais. Uma dimensão importante da socialização estudantil refere-se à avaliação subjetiva-pessoal dos estudantes do contexto universitário. Os estudantes abordam seu meio ambiente de estudo como um processo interpretativo, identificando-se de maneira individual ou coletiva as pistas de ação possíveis.

Palavras-chave: Percepção de estudantes. Perspectiva de aprendizado. Práticas de estudos.

\section{The relation with learning at the university and the study environment}

\section{Abstract}

We examine the link between subjective evaluation of students study context and the learning relation in the University. It is founded in a qualitative survey carried out between 2005 and 2008 with students of the Letters course, Human Sciences and Social Sciences in five Parisian universities. The investigation reveals the logic learning-learn and its reflexivity in the course and dynamics that gives sense to the individuals trajectories. An important dimension of student socialization is the students' subjective-personal evaluation of university context. The students approach their learning environment by an interpretative process, identifying themselves in an individual or collective manner with possible action clues.

Keywords: Student perceptions. Learning perspective. Students' activity. 
A relação com o aprender na universidade e o meio ambiente de estudos

\section{La relación con el aprender en la universidad y el medio ambiente de estudios}

\section{Resumen}

Se examina la ligación entre la evaluación subjetiva del contexto de estudios pelos estudiantes y la relación con el aprender en la Universidad. Esta análisis es basada en una encuete cualitativa hecha entre 2005 e 2008 con los estudiantes de Letras, Ciencias Humanas e Ciencias Sociales de cinco universidades parisienses. La investigación revelo una lógica aprendiendo-aprender y su reflexividad en el camino y dinámicas que dan sentido a las trayectorias individuales. Una dimensión importante de la socialización estudiantil se refiere a la evaluación subjetiva-personal de los estudiantes del contexto universitario. Los estudiantes abordaron su medio ambiente con un proceso interpretativo se identificando de manera individual o colectiva a las pistas de acción posibles.

Palabras-claves: Percepción de los estudiantes. Perspectiva de aprendizaje. Prácticas de estudios.

\section{Introdução}

As pesquisas sobre as práticas de estudos, a socialização ou desempenho dos estudantes tendem, geralmente, a se interessar por variáveis como o percurso escolar anterior, a origem social, as motivações e os projetos e as condições de vida. Referindo-se a essas pesquisas, é possível dizer que existe, constantemente, uma correlação estatística significativa entre o capital cognitivo anterior, características pessoais e familiares ou condições materiais e desempenho universitário. Essas pesquisas tendem a se inscrever no campo da sociologia da reprodução, iniciado por Bourdieu e Passeron (1964) na França.

A teoria da reprodução é centrada sobre a posição social do indivíduo (o capital cultural e linguístico desenvolvido no interior da família) em seu futuro escolar. Essa sociologia refere-se a uma leitura determinista da relação entre sistema educativo e sociedade, sustentando que as disposições físicas são essencialmente estruturadas pela ordem social. Entretanto, uma corrente 
emergente da pesquisa em sociologia da educação tenta levar a efeito as variáveis ligadas ao contexto de estudo e às interações desenvolvidas nas situações escolares ou universitárias. No domínio do ensino superior, essa nova geração de pesquisas, sem negar a importância do habitus, procura examinar a aprendizagem universitária ligada à filiação dos estudantes, no sentido de pertencimento às áreas de formação no ensino superior, buscando descrever sua socialização, mobilização intelectual e engajamento acadêmico.

$\bigcirc$ meio ambiente de estudo remete à organização pedagógica (modalidade, recursos), aos objetivos formais, às exigências e às atividades pedagógicas efetivas, ao contexto humano e às interações interpessoais. Refere-se tanto ao dispositivo pedagógico (estrutura curricular) quanto ao contexto social designando a organização social das oportunidades de interações (a estrutura extracurricular). $\bigcirc$ meio ambiente de estudo não se constitui, unicamente, de um quadro que revela os processos sociais de ordem geral, sendo igualmente um lugar de atividades com características próprias. As interações sociais no meio ambiente de estudo compreendem as relações entre estudantes, professores, pessoal administrativo, grupo de pares e dispositivos pedagógicos. Essas relações definem o clima social geral (contexto humano) de uma filiação de estudos. A noção de meio ambiente de estudo designa assim um espaço/tempo de formação que leva em consideração os elementos constitutivos do meio social e pedagógico da aprendizagem. Trata-se de uma perspectiva "ecológica" que tenta integrar o impacto do meio ambiente sobre os atores e as interações.

Interessar-se ao meio ambiente de estudo significa que a cognição e a socialização não são separáveis (ALAVA; ROMAINVILLE, 2001). Uma abordagem "holista" tenta associar melhor o aprender e o ensinar examinando o aprendente no contexto do estabelecimento e de sua filiação de estudos. Essa abordagem não considera a aprendizagem um processo puramente cognitivo, tampouco reduz o estudante a uma identidade mental estatística e discreta (MANN, 2008). Evocando a situação educativa, Weil (1993) pensa também que não somos unicamente um cérebro, mas sim seres humanos que não se restringem às características de nosso grupo de pertencimento. Para destacar o lugar da vida humana e relacional nas atividades cognitivas, Abram (1996) se refere à Merleau-Ponty que nos convida a reconhecer que, no cerne das nossas cognições, mesmo as mais abstratas, estão presentes o sensual e o sensível. A experiência estudantil constrói-se em 
A relação com o aprender na universidade e o meio ambiente de estudos

situação porque as lógicas e os processos sociais e individuais se misturam, entram em interação e se transformam. Em outras palavras, "o quê" o estudante vive e compreende é inseparável de "como" ele vive, compreende e organiza o ato de aprender.

$\bigcirc$ efeito do meio ambiente de estudo não foi examinado da mesma maneira pelos diferentes autores em sociologia, em ciências da educação ou em psicologia. Em uma pesquisa pioneira, Martone Säliö (1 976) sustentaram que a atitude dos estudantes tendia a não ser a mesma com a mudança de contexto. As pesquisas de Tinto (1987), sobre o fracasso dos estudantes no começo de seu percurso universitário e a continuação futura dos estudos, orientam-se essencialmente para a socialização e o impacto do meio ambiente de estudo. Para ele, a falta de ligação significativa com o meio de estudos e o isolamento do estudante contribuem para acelerar o processo de abandono universitário. Segundo o autor, as comunidades de aprendizagem constituem-se a partir de disciplinas "compartilhadas", funcionando como uma rede e propõem atividades que se completam no plano pedagógico.

$\bigcirc$ meio de aprendizagem contribui para dar ao estudante a vontade de aprender e o sentimento de aprender com pertinência, ou, inversamente, 42 esse meio pode tornar-se um obstáculo para a aprendizagem. $\bigcirc$ impacto do meio ambiente de estudo foi também destacado pela enquete realizada com uma amostra de 2300 estudantes de vinte e quatro estabelecimentos universitários nos Estados-Unidos, examinando as variáveis ligadas ao meio ambiente familiar, no percurso do secundário, a mobilização individual do estudante e o contexto universitário (ARUM; ROKSA, 2010). Três temáticas ligadas à aprendizagem foram avançadas nessa pesquisa: o pensamento crítico, o raciocínio analítico e a escrita universitária. Os resultados levantados por esses dois pesquisadores permitem ilustrar o impacto simultâneo dos fatores individuais e universitários sobre a qualidade de aprendizagem dos estudantes. $\bigcirc$ contexto acadêmico, a exigência e as demandas pedagógicas constituem os mais fortes fatores institucionais que têm um impacto direto sobre a aprendizagem dos estudantes.

Outro eixo presente na pesquisa sobre o desempenho acadêmico focaliza-se no impacto direto dos componentes do encaminhamento pedagógico diante da qualidade de aprendizagem do estudante (GARRISON; ANDREWS; MAGNUSSON, 1995; BIGGS, 1990|. Trata-se de examinar a relação entre, de um lado, a concepção de ensino mobilizada pelo professor, seus métodos 
e suas escolhas pedagógicas, suas exigências, os recursos fornecidos e as interações desenvolvidas no interior de cada situação (BOEKAERTS, 200 1); de outro lado, os resultados e a qualidade de aprendizagem do próprio estudante. Forest (1998) designa um momento de aprendizagem como um encontro entre a contribuição do professor, o meio ambiente pedagógico e a mobilização do aprendente.

As pesquisas sobre a motivação estudantil no contexto dos estudos tendem igualmente a adotar essa abordagem "ecológica" se interessando às características do meio social e educativo (PINTRICH, 2003) no qual a experiência de imersão estudantil se realiza. Järvela, Järvenoja e Veermans (2008) também pensam que as motivações de aprendizagem dos estudantes não podem ser dissociadas do contexto social e cultural. A noção de "dinâmica motivacional", trabalhada por esses três universitários finlandeses, tenta examinar esse fenômeno como um encontro entre a perspectiva individual e a perspectiva do grupo em um contexto universitário. No modelo sociocognitivo desenvolvido por Zimmerman (1989) destinado ao estudo da motivação, a busca de objetivos pessoais e a autorregulação entre os estudantes se interessa amplamente pelas condições ambientais, como o apoio dos professores e os comentários dos seus pares.

Com base na leitura das pesquisas sobre o desempenho universitário, parece que o meio ambiente de estudo é geralmente examinado através de um duplo impacto sobre a qualidade da aprendizagem do estudante. De um lado, o funcionamento efetivo e a pertinência do contexto de aprendizagem intervêm diretamente no processo de aprendizagem, por outro lado, a maneira pela qual os estudantes percebem e apreciam a organização pedagógica e o conteúdo do ensino torna-se um fator importante de sua mobilização universitária e intelectual. Dito de outra maneira, a eficácia e a pertinência do contexto de aprendizagem devem ser percebidos como tais pelos próprios estudantes. É essa percepção que influencia o sentido dado a ser estudante e aprender na universidade. Segundo essa lógica, a avaliação subjetiva do estudante constitui a mediação entre o contexto e a perspectiva de aprendizagem que ele desenvolveu (PAIVANDI, 2012). A representação do contexto pedagógico constitui, então, um fator tão importante da situação que ela determina, ao menos, em parte, a continuidade na universidade. É nesse quadro que se misturam os fatores objetivos e subjetivos do contexto universitário. Os fatores objetivos coabitam com as interpretações individuais, que mudam e dependem do contexto 
A relação com o aprender na universidade e o meio ambiente de estudos

e da experiência individual e coletiva. Weidman (1989) e Romainville (1998) colocam o contexto normativo e as interações sociais lado a lado para descrever a experiência universitária, ainda que destaquem a sua interdependência.

\section{A qualidade da aprendizagem na universidade}

A noção de desempenho universitário dos estudantes se interessa essencialmente ao sucesso formal laprovação em disciplinas, conclusão do ano acadêmico, passagem para um nível superior ou obter um diploma). Por exemplo, os indicadores franceses estabelecidos pelo Ministério de Educação Nacional são construídos em relação aos dados "objetivos": o sucesso universitário se avalia, nesse quadro, segundo o nível final dos estudos e segundo o ritmo do percurso. Os estudantes com melhor "desempenho" são aqueles que chegam mais rápido ao fim do seu percurso.

Essa leitura do desempenho parece ser reducionista porque existe outra dimensão no percurso universitário dos estudantes que repousa sobre a qualidade da aprendizagem. A qualidade da aprendizagem remete particular-

44 mente às finalidades científicas, intelectuais e profissionais dessa instituição. A universidade deve então ser compreendida pela relação entre o aprendizado desenvolvido pelo estudante, assim como na diferença com o período acadêmico precedente.

Os estudantes já conhecem a cultura escolar antes de chegarem à universidade: um emprego de tempo carregado e cursos regulares, uma assiduidade obrigatória, as unidades pedagógicas permanentes sob a forma de classes de alunos, os professores na proximidade com os seus alunos, um controle regular dos conhecimentos, um programa bem delimitado pelos manuais, etc. Nesse modelo, o aprendente é constantemente colocado em uma lógica de acumulação de conteúdos de matérias díspares e da restituição durante os controles.

Na universidade, a organização pedagógica muda de maneira radical e o saber deveria mais que nunca estar no centro da educação intelectual, crítica e profissionalizante. A universidade oferece a possibilidade de explorar um domínio do saber, de aprender no quadro de uma disciplina fundada sobre uma linguagem e um conjunto de discursos, de teorias e de construções abstratas e complexas. A universidade propõe que se trabalhe em um projeto 
pessoal ou profissional, que se desenvolva uma nova autonomia intelectual e social. Essa transformação implica uma aculturação ao mundo universitário e uma mudança qualitativa de atitude diante do ato de aprender.

É nessa perspectiva que a qualidade da aprendizagem, desde os anos 1960, tornou-se um objeto de pesquisa reconhecido. A pesquisa de Perry, conduzindo uma enquete longitudinal sobre os estudantes de Harvard nos anos 1960, centrada sobre os modos de apropriação do saber universitário entre os estudantes, constitui um trabalho pioneiro nesse domínio. Essa pesquisa permitiu identificar as condutas diferenciadas dos estudantes diante do ato de aprender na universidade e a evolução da postura "epistêmica" durante o percurso universitário (PERRY, 1970). Essa pesquisa destaca uma escala de nove posições repartidas em três categorias: a posição dualista, a apreensão do relativismo e a elaboração do relativismo. Nessa tipologia, os estudantes oscilam entre o dualismo simplista e trivial, fundado sobre o caráter dual do conhecimento (verdadeiro ou falsol e a abordagem relativista baseada na apropriação refletida do saber e o sentido pessoal atribuído à aprendizagem. A postura relativista permite a dúvida, a ambiguidade e a leitura questionadora das informações e das teorias recebidas: nesse caso, o estudante é o sujeito de sua formação e interpreta as coisas com uma abordagem crítica (PERRY, 1970).

Outra pesquisa marcante referente à temática foi realizada por universitários suecos (MARTON; SÄLÖ, 1976; SVENSSON, 1997) sobre a maneira de aprender na universidade. Seus trabalhos feitos sobretudo na perspectiva psicológica se interessam pela concepção estudantil da aprendizagem universitária. Elas tentam examinar como o estudante organiza e dá sentido às tarefas ligadas à aprendizagem. Säliö (1 979), na sua pesquisa sobre a Universidade de Göteborg, encontra cinco maneiras diferentes de atribuir sentido à aprendizagem no contexto universitário: 1) a aprendizagem é percebida como o aumento quantitativo do saber - aprender é saber muitas coisas; 2) a aprendizagem é percebida como a memorização para estocar duradouramente os conhecimentos e recuperá-los durante as provas; 3) a aprendizagem é considerada como a aquisição de teorias e de métodos destinados a serem colocados em prática na realidade; 4) a aprendizagem é destinada à compreensão, à construção do sentido ou à abstração do significado das relações no interior da matéria; 5) a aprendizagem significa a interpretação e a compreensão de alguma coisa, mas de outra forma, em uma transformação qualitativa de si, uma atualização de potencialidades. 
Desenvolvendo o mesmo tipo de pesquisa, Marton e seus colaboradores (1993) acrescentaram uma nova concepção de aprendizagem centrada sobre uma mudança da pessoa, uma mudança de olhar quanto ao seu posicionamento no mundo. Os autores trabalharam igualmente sobre a noção de "abordagem do aprendizado", designando a qualidade da aprendizagem (processos e resultados). O termo "abordagem" é utilizado pelos autores para designar uma forma de compreensão que destaca o processo de aprendizagem e a maneira com a qual o estudante aborda o conteúdo informacional. Nessa tipologia, os estudantes desenvolvem as três concepções e tendem a aprender de uma forma fragmentada, focalizando-se sobre os dados de maneira isolada. Essa abordagem, tendendo a desconsiderar a complexidade e o acesso às concepções sofisticadas, é designada como "abordagem superficial". Diante dessa primeira categoria, propõe-se uma abordagem em profundidade reagrupando as três concepções anteriores sobre a significação dos dados.

As pesquisas realizadas desde os anos 1980 convergem e relacionam a abordagem da aprendizagem e a qualidade do resultado. Essas pesquisas revelam que os estudantes se diferenciam pela maneira de fazer e de se investir nas tarefas de estudo, a relação com o saber e o sentido atribuído à aprendiza-

46 gem (SVENSSON, 1997; ASTIN, 1985; BLOOMER; HODKINSON, 2000; ROMAINVILLE, 1998).

\section{A enquete sobre a relação com o aprender}

Minha investigação feita com o grupo de estudantes inscritos nas cinco universidades da região parisiense tentou examinar a relação com o aprender, em relação com o contexto universitário. Essa pesquisa inscreve-se na dinâmica dos trabalhos sociológicos sobre a socialização e a filiação intelectual dos estudantes na universidade, explorando uma nova pista focalizada sobre a qualidade de sua aprendizagem. Trata-se de identificar as diferentes figuras do aprendente na universidade e de examinar os fatores contextuais que contribuem para diferenciar os estudantes no investimento das tarefas de estudos. A pesquisa se interessou pela ideia de interdependência das esferas de atividades e processos sociais vinculadas a temporalidades mais amplas do que a experiência universitária em curso. Tentei examinar a conectividade transversal (lateral) e temporal de um percurso de aprendizagem. Em outras palavras, 
buscou-se apreender a maneira como a aprendizagem se conecta (lateral e transversalmente) com o contexto e as experiências de vida do aprendente, assim como de que maneira um conjunto de experiências de aprendizagem conecta-se (temporalmente) com outras que a precedem ou se seguem (BLOOMER;HODKINSON, 2000).

a) Apresentação da enquete

A enquete qualitativa, realizada entre 2005 e 2008, teve como objetivo apreender o sentido dado pelo estudante ao ato de aprender na universidade e as interações com o meio ambiente de estudo. No meu trabalho, a relação com o aprender designa a concepção de apropriação do saber em um contexto formal. $\bigcirc$ aprendente tende a dar um sentido ao ato de aprender e a mobilizar o processo do saber como uma atividade criativa para pensar, desenvolver-se, agir e transformar-se em autor do saber. Assim, a relação com o aprender universitário se interessa aos motivos do estudante inscrever-se em uma filiação dada ao sentido que a universidade, o saber universitário e as atividades de aprendizagem se apresentam para ele. Trata-se de uma leitura alternativa da realidade universitária para evitar as dicotomias reducionistas como sucesso/fracasso ou bom desempenho/mau desempenho.

Trabalhar sobre a relação com o aprender na universidade é examinar o sujeito aprendente confrontado com a necessidade de aprender e, por suas atividades, sua apropriação desse universo específico que é o meio universitário. Trata-se de uma dialética entre sentido e eficácia, ou ainda entre atividade e subjetividade.

Longe de ser um processo simplesmente cognitivo, aprender implica as múltiplas relações ligando o indivíduo e seu mundo aos outros e ao meio ambiente social. A relação de cada sujeito com o aprender é singular e compreende a experiência vivida pelo aprendente e a maneira como ele a interpreta. A relação com o aprender tem como preocupação o processo de aprendizagem em um contexto formal ou informal e com a questão "como aprender?". Assim, é fundamental a questão do sentido, cristalizando a dialética do encontro entre um sujeito e uma situação de aprendizagem.

As entrevistas (com 115 estudantes) foram organizadas ao redor de um tema central: qual é o sentido da aprendizagem na universidade? E como 
A relação com o aprender na universidade e o meio ambiente de estudos

se aprende na universidade? No decorrer de uma discussão aberta e compreensiva, os estudantes foram convidados a falar de seu percurso anterior, de sua motivação para escolherem seu curso de formação, de seu projeto, das disciplinas nas quais eles tinham "aprendido bem" e de disciplinas "perdidas", do clima das disciplinas, dos modos diferenciados de aprendizagem de acordo com as disciplinas, de suas relações com os professores e com seus camaradas, da utilidade da aprendizagem universitária (saber e saber fazer), da ligação entre as diferentes disciplinas. A entrevista procurou apreender o ponto de vista dos estudantes sobre seu percurso e sua relação com o aprender na universidade, as ideias com as quais eles definem a sua situação universitária.

\section{Principais características da população ( 115 estudantes)}

\section{Estudantes Universitários - Região Parisiense 2006/2008}

\begin{tabular}{|l|c|c|}
\hline \multicolumn{1}{|c|}{ Variáveis principais } & Efetivos & $\%$ \\
\hline Masculino & 41 & $36 \%$ \\
Feminino & 74 & $64 \%$ \\
\hline - de 22 anos & 44 & $38 \%$ \\
22-25 anos & 35 & $31 \%$ \\
26-30 anos & 23 & $29 \%$ \\
+ de 30 anos & 13 & $11 \%$ \\
\hline Nível de estudos superiores durante a entrevista & & \\
Segundo ano & 9 & $8 \%$ \\
Terceiro ano & 57 & $50 \%$ \\
Quarto ano & 32 & $28 \%$ \\
Quinto ano & 16 & $14 \%$ \\
\hline Família "favorecida" (diploma superior ou situação/categoria & & \\
socioprofissional executivo e profissão liberal) & 34 & $30 \%$ \\
Executivo médio & 36 & $31 \%$ \\
Família popular (operário, empregado) & 24 & $21 \%$ \\
Outro & 21 & $18 \%$ \\
\hline
\end{tabular}

A investigação longitudinal conduzida junto a um grupo de dez estudantes tinha como objeto examinar as mesmas questões em sua evolução no decorrer do tempo. Essa observação foi rica, pois a relação prolongada com os estudantes permitiu se detalhes refinados e se compreender as interações 
entre o estudante e o meio ambiente de estudo, a evolução de sua relação com o aprender na universidade. Foi muito interessante o acúmulo da observação longitudinal e as entrevistas únicas (uma só vez): isso permitiu a revelação e a identificação de regularidades emergindo da variedade dos percursos universitários.

conjunto desses dados não nos indicou o que os estudantes efetivamente aprenderam, mas o que eles dizem ter aprendido. Não se trata, então, de um balanço "objetivo" a partir de uma grade de avaliação rigorosa (aliás, eu não tive acesso aos resultados dos estudantes), mas unicamente uma autoavaliação em um dado momento do seu percurso universitário e de um ponto de vista de sua situação. Trata-se de um trabalho fenomenológico apoiando-se sobre a "realidade de segundo nível" construída pelo aprendente em contexto. Os estudantes evocam o que para eles se apresenta de importante, de valor, em sua aprendizagem universitária.

\section{A perspectiva da aprendizagem}

Para dar conta da relação com o aprender dos estudantes, traduzindo a qualidade de sua aprendizagem universitária, escolhi a palavra "perspectiva", diferente dos termos "abordagem", "concepção" ou "orientação", utilizados em outras pesquisas (segundo a psicologia cognitiva). A perspectiva, na tradição da escola de Chicago, refere-se à maneira ordinária de pensar e de sentir de uma pessoa que se encontra em uma dada situação (BECKER; GEER; HUGHES; STRAUSS, 1961 1. Para os etnógrafos dessa escola, a perspectiva designa o ponto de vista dos professores e dos alunos sobre a situação, ou ainda a maneira pela qual os alunos percebem e julgam a escola, o trabalho escolar e o trabalho dos professores. Essa escolha se explica pelo encaminhamento sociológico da enquete e sua inscrição interacionista (COULON, 1993). As pesquisas suecas, inglesas ou australianas, já mencionadas, utilizaram geralmente um encaminhamento baseado na produção de um trabalho pelos estudantes, seguindo de uma entrevista. No meu trabalho, a perspectiva significa um ponto de vista sobre a realização na qual o estudante é o autor. Pode-se definir a perspectiva de aprendizagem como o conjunto articulado de ideias, de esquemas e de ações que um estudante mobiliza para apreender as tarefas ligadas à aprendizagem universitária. 
A relação com o aprender na universidade e o meio ambiente de estudos

Assumi a perspectiva como um conceito fenomenológico em relação reflexiva com a "definição da situação", que é simultaneamente produtora e produzida. As perspectivas são inseparáveis das situações nas quais elas aparecem, ou nos quadros nos quais os indivíduos dão sentido ao mundo ao seu redor (MEAD, 2005). As perspectivas estão ligadas à ação e permitem aos estudantes construir espaços de realidade no interior da universidade. A relação como o aprender constitui a base de um modus vivendi entre o estudante e a universidade e o desenvolvimento de uma perspectiva mostra como os estudantes mobilizam esquemas de ações coerentes para realizar as tarefas ligadas aos seus estudos. O caráter situacional da perspectiva convém ao encaminhamento escolhido, pois os estudantes têm a tendência a desenvolver sua perspectiva por meio de uma atividade de construção e estabelecimento de uma nova identidade.

A perspectiva, então, se constrói e se transforma através da socialização universitária. Toda socialização constitui um fenômeno interacional e um processo de aquisição de saberes que se impõem ao desenvolvimento de trocas e nos laços sociais. Segundo Mead (2005), o processo de conhecimento é uma atividade situada de organismos se readaptando sem cessar a meios 50 que eles transformam, em uma dinâmica na qual procedem o cognoscente e o conhecido. Trata-se para o estudante de compreender as mensagens e comportamentos do outro e de se fazer compreender pelo outro através de uma "intersubjetividade pragmática" (SCHUTZ, 1967). No centro dos comportamentos do sujeito social, se encontram a intencionalidade (motivos, objetivos) e a capacidade para interpretar as ações dos outros. Para chegar à plena consciência da subjetividade do estudante, é preciso examinar suas intenções no meio ambiente universitário. A socialização é um processo que permite ao estudante se apropriar do papel dos outros e de construir assim seu "Eu" enquanto estudante. Levar em consideração o papel do outro remete ao processo de adaptação mútua, de apropriação recíproca dos papéis que se realizam nas interações visíveis e invisíveis do ambiente universitário. Esse processo de adaptação permite a interiorização de atitudes, de dispositivos, de valores, de crenças e de expectativas.

A problemática e os instrumentos metodológicos mobilizados na minha enquete inscrevem-se no quadro teórico da sociologia interacionista. $\bigcirc$ encaminhamento qualitativo apoiado pelo trabalho longitudinal me permitiu melhor apreender o ponto de vista estudantil sobre o sentido acordado a sua presença 
na universidade e sua perspectiva de aprendizagem. Todos os estudantes entrevistados, dos quais selecionei alguns trechos neste escrito, estão identificados por pseudônimos, juntamente com o seu curso e ano da entrevista. Trabalhando sobre o corpus dos dados, tentei elaborar uma tipologia das relações com o aprender entre os estudantes, em relação com o contexto universitário na França. A tipologia elaborada compreende quatro perfis: a perspectiva compreensiva, a perspectiva de desempenho, a perspectiva minimalista e a perspectiva de desengajamento.

a) A perspectiva "compreensiva"

A perspectiva compreensiva, presente em um estudante sobre cinco na minha amostra, responde aos traços esperados das exigências acadêmicas na universidade. Trata-se de um estudante que privilegia a compreensão e o sentido, tentando se apropriar do saber de uma maneira personalizada, mostrando-se curioso e interessado pelo domínio de seus estudos. Esse estudante tem uma relação dinâmica e menos contábil do ato de aprender, sendo o prazer da aprendizagem a fonte dessa perspectiva:

Eu me sentia bem nas disciplinas, um tema interessante e um curso simpático é o ideal para aprender [...]. Alguns textos eram realmente difíceis. Eu não anotava tudo, mas quando eu não sabia alguma noção ou não a compreendia bem, ia à biblioteca ou fazia uma pesquisa na Internet (MARION, Ciência Política, 2008).

Essa perspectiva favorece a compreensão personalizada do estudante e mobiliza seus saberes anteriores. $\bigcirc$ aprendente está envolvido com o sentido atribuído ao saber fora do sentido compartilhado com os outros. Esse "valor agregado" contribui para a apropriação do saber dando-the um sentido pessoal. A atividade de aprendizagem, nesse grupo, tem uma dinâmica interna mobilizando um tipo de relação com o mundo (com os outros e consigo mesmo). acesso no nível mais elevado na atividade de aprendizagem no interior da universidade proporciona um prazer:

Eu me encontro entre os verdadeiros literários, algumas disciplinas têm um ambiente incrivelmente rico, todo mundo é interessado, o fato que os professores são os pesquisadores nos dá vontade de ir o mais longe possível [...] (SOPHIE, Letras, 2007). 
A relação com o aprender na universidade e o meio ambiente de estudos

Os estudantes desse grupo chegam a descrever o sentido epistêmico de sua aprendizagem e de sua presença na universidade. $\bigcirc$ engajamento pessoal na perspectiva compreensiva é um elemento determinante, o estudante sabe por que ele aprende e se percebe o seu comprometimento epistêmico. Os estudantes são, por essa razão, geralmente muito sensíveis ao conteúdo das disciplinas, à tomada de posição dos docentes e a sua abordagem. A relação com a linguagem é outro indicador que permite a identificação dos estudantes que se encontram em uma perspectiva compreensiva. Quando o saber tem um sentido, a linguagem não é somente uma forma de comunicação escrita ou oral, mas também um meio de pensamento. A aprendizagem participa no desenvolvimento e na transformação de si, na associação da experiência pessoal com a construção de um "eu" sujeito aprendente. As teorias e os conceitos permitem algumas vezes transformar a experiência cotidiana em objeto de reflexão e contribuem no avanço de sua relação com o mundo:

Algumas disciplinas me ajudam a compreender melhor meu trabatho. Eu cursei uma disciplina muito interessante sobre a violência, esse ensino mudou um pouco minha visão sobre a conduta dos jovens em certos bairros. Eu trabalho há sete anos em uma associação e não via esse problema desse jeito [...] (AGATHE, Sociologia, 2006).

Nesse grupo da perspectiva "compreensiva", proporcionalmente são mais numerosos aqueles que fazem o bacharelado nas séries iniciais, os estudantes inscritos no $3^{\circ}$ e $4^{\circ}$ anos, os estudantes provenientes das famílias "favorecidas" e aqueles que moram em Paris.

\section{b) A perspectiva minimalista}

Na minha enquete, a perspectiva minimalista atinge um estudante em três (34\%, 39 estudantes). Ela representa um aprendente que se contenta com um mínimo indispensável para validar as disciplinas do seu curso, livrar-se das tarefas e conformar-se às prescrições pedagógicas. Para esse grupo, as expectativas diante da universidade são geralmente baixas: os referidos estudantes buscam, antes de tudo, um diploma que facilite o acesso a um emprego. Então, esses estudantes não manifestam grande interesse por seus estudos e preocupam-se menos com o que aprendem do que com a utilidade que esperam de 
sua formação. Assim, Saba, um exemplo desse tipo de estudante, estima que algumas disciplinas são "teóricas demais" e "distantes do trabalho de professor":

Senti durante a disciplina que, como eu, poucos estudantes estavam interessados no ensino proposto. Tudo que se quer é ser aprovado na disciplina. Ao lado disso, não senti que o professor estivesse realmente com vontade de nos envolver no seu ensino. Seja porque ele não soube como fazer, seja porque ele não nos viu motivados (SABA, Ciências da Educação, 2008).

A maneira como se realizarem os trabalhos universitários é, igualmente, um indicador que revela esse estado de espírito. Os estudantes minimalistas dizem muitas vezes ter feito um trabalho com o único objetivo de serem aprovados na atividade. O objetivo consiste em otimizar a relação custo/benefício no trabalho universitário. O tempo consagrado aos estudos é contado, como se eles trabalhassem para ganhar um salário. Por essa razão, o tempo de elaboração e de maturação torna-se "insuportável":

As disciplinas práticas me interessam mais, pelo menos é algo concreto. Algumas delas são decididamente incompreensíveis: não sei para que servem essas teorias complicadas. Muitos dos meus colegas estão no mesmo caso que eu [...] (MELISSA, Ciências da Linguagem, 2007).

Esses estudantes dizem constantemente favorecer os métodos escolares como a memorização e a aprendizagem de "coisas úteis" para passarem nas disciplinas. As disciplinas thes parecem, na sua compreensão, como uma justaposição de atividades fragmentadas; o pensamento e a vida intelectual são julgados supérfluos, pouco úteis. As pessoas que fizeram um certificado tecnológico (exame de nível médio), que tiveram um percurso escolar difícil e que estavam inscritas nos $1^{\circ}$ e $2^{\circ}$ anos, pertencendo às famílias populares, estão, proporcionalmente, em maior número nesse grupo.

\section{c) A perspectiva de desempenho}

A perspectiva de desempenho compreende um pouco mais de um terço dos estudantes interrogados na minha enquete. Ela reflete uma posição intermediária entre as perspectivas compreensiva e minimalista. Os estudantes 
A relação com o aprender na universidade e o meio ambiente de estudos

desse grupo pensam em ter sucesso, aprender coisas em relação à profissão e obter seu diploma com uma boa menção. Esses elementos representam bem uma posição estratégica do estudante, fundada numa boa organização dos estudos e na assimilação das somas cognitivas exigidas.

$\bigcirc$ estudante desse grupo concede uma importância efetiva para os seus estudos e para o sucesso escolar, tenta obter as melhores notas, busca compreender melhor as exigências dos professores para as provas, faz um trabalho regular e utiliza todos os meios para melhorar o seu desempenho:

Eu trabalho com a minha amiga, ambas anotamos as aulas e trocamos as notas para completar. Revisamos juntas e isso ajuda muito. professor nos deu três obras de referência para aprofundar a disciplina. Ele não disse que era obrigatório, mas eu penso que isso vai contar para o exame parcial, todo mundo diz que as aulas não são suficientes para se ter uma boa nota [...] (LAURA, Direito, 2008).

Kamel é um estudante assalariado que trabalha como jornalista, enquanto prossegue com seus estudos no curso de comunicação. Ele aprecia a

54 pertinência do saber universitário referindo-se a sua utilidade prática para sua profissão:

Tenho todo tempo uma preocupação de eficácia. A cada fim de disciplina, tento ver se esta foi aproveitável e se há uma real evolução no meu trabalho de jornalista (KAMEL, Comunicação, 2006).

Esse tipo de perfil corresponde à lógica do "saber-objeto" e valoriza os bons hábitos de trabalho. Os estudantes desse grupo são geralmente receptivos, atentos à natureza das tarefas e das exigências acadêmicas. Os estudantes originários de famílias favorecidas e médias são proporcionalmente mais numerosos nesse grupo.

d) A perspectiva de desengajamento

A última perspectiva na tipologia estabelecida remete aos estudantes em situação de desfiliação (1 1\%). Essa atitude traduz o estado dos estudantes em via de marginalização, sentindo-se excluídos: 
Fui reprovado em algumas disciplinas e eu não compreendo mais nada, uma garota me emprestou suas anotações, mas não está claro, não consigo me ligar [...] (NIANE, História, 2007).

Niane não deseja inscrever-se em história: sua primeira escolha dirigia-se para um curso de serviço social. Essa perspectiva é comumente associada a uma orientação caótica (inscrição automática, erro de apreciação). $\bigcirc$ desinteresse pelos estudos provoca logicamente uma falta de gosto pelo saber oferecido pela formação:

Eu não compreendo os professores aqui, no liceu (ensino médio) via-se um pouco mais claramente, aqui, nos fazem qualquer coisa, é inútil tudo isso, o espírito crítico, a epistemologia, a metodologia [...] Tudo isso é tão complicado (MICHEL, Sociologia, 2006)

Para Alain, inscrito em psicologia:

O intervalo é uma liberação de tensões. Aproveita-se para falar do professor que repete sem parar a mesma coisa: Freud, por aqui, Winnicot, por lá [...] Isso satura. Pensa-se nas provas parciais, como será preciso vomitar tudo isso [...] (ALAIN, Psicologia, 2008).

Alguns não se veem à altura das exigências acadêmicas, como Pauline, estudante de direito que pensa em sua reorientação. Ela não se sente capaz de seguir e de ser aprovada nas disciplinas. Observa-se que os estudantes estrangeiros, inscritos nos $1^{\circ}$ e $2^{\circ}$ anos ou aqueles de origem em famílias populares, estão super-representados nesse grupo.

Minhas entrevistas com os estudantes mostraram que eles não mobilizam sistematicamente a mesma perspectiva em todas as disciplinas. A perspectiva compreensiva não implica necessariamente a aprendizagem de todas as disciplinas com a mesma qualidade. Uma perspectiva representa a atitude dominante, mas não exclusiva. Por diversas razões (falta de tempo, tema desinteressante...., pode-se aprender superficialmente uma disciplina e desenvolver, em outra, uma aprendizagem compreensiva.

Por outro lado, fazendo o seu caminho, os estudantes tendem a abordar níveis mais sofisticados de aprendizagem. Solicita-se a eles a realização de trabalhos personalizados (relatórios, dossiês, ensaios), fazer uma enquete ou realizar uma monografia de pesquisa, conduzir projetos, apresentar uma 
A relação com o aprender na universidade e o meio ambiente de estudos

exposição pessoal ou coletiva explorando um domínio ou uma questão teórica. Trata-se de explorar e manipular dados, ideias, teorias e conceitos, para compreender um fenômeno, uma questão social. Para os estudantes que adotam uma perspectiva compreensiva ou de desempenho, essas experiências tornam-se uma fonte insubstituível para aprofundar e dominar o saber e sua mobilização.

\section{Compreender as variações}

A existência entre os estudantes de diferenças consideráveis na relação com o aprender leva-nos a questionar as razões dessas variações. $\bigcirc$ exame das variáveis sociológicas tais como o sexo, a origem social e as condições de vida não permite estabelecer uma relação significativa entre uma dada perspectiva e essa ou aquela característica social ou individual. $\bigcirc$ peso e os efeitos dessas variáveis "não contextuais" são efetivos, porém relativamente limitados. Ambos parecem ter exercido seu impacto durante o percurso escolar através dos diferentes "filtros" feitos depois da escola primária. Segundo a origem social, o sexo ou o percurso escolar anterior, os alunos não têm a mesma chance de chegar ao ensino superior e às suas diferentes formações. Entretanto, o percurso escolar anterior (dificuldades encontradas durante o ensino médio) constitui um fator discriminatório relativamente importante. A oposição mais clara se observa entre os estudantes tendo feito no liceu (ensino médio) o curso geral e os que fizeram cursos tecnológicos.

Entre os fatores tendo tido uma influência sobre a relação com o aprender, é preciso destacar aqueles concernentes ao meio ambiente de estudo. Em minha enquete, a noção de meio ambiente de estudo (compreendida como uma relação espaço-tempo) é utilizada para levar em consideração os elementos constitutivos do contexto social e pedagógico da aprendizagem. Se nos baseamos sobre os propósitos dos estudantes, o meio ambiente de estudo se refere às disciplinas dos cursos e aos departamentos, reagrupando geralmente quatro tipos de componentes: o programa (conteúdos), a concepção de ensino (avaliação, métodos pedagógicos, suportes técnicos), o contexto humano (interações pessoais) e o status da disciplina (obrigatória ou opcional). Quando solicito aos estudantes para falarem de suas disciplinas, comumente eles as descrevem julgando-as: "as disciplinas são insuportáveis sobre todos os planos", "uma disciplina muito escolar", "a disciplina não é ruim, mas sua organização é 
nula". Ocorre o mesmo com os professores: os estudantes tendem a não distinguir o conteúdo de uma disciplina da pessoa que a ensina.

$\bigcirc$ meio ambiente de estudo constitui uma matriz de elaboração simbólica e subjetiva das representações. Meyer e Muller (1990) evocam a orquestração para designar a resposta dada pelo estudante ao contexto. $\mathrm{Na}$ minha pesquisa, em geral os estudantes exprimiram três tipos de julgamentos globais em relação ao contexto de seus cursos de formação:

a) A percepção entusiástica (a ideia global é positiva, os componentes pedagógicos são apreciados, os aspectos negativos estão ausentes ou minimizados):

[...] a disciplina está baseada no texło distribuido na semana precedente. Esse método me convém perfeitamente; eu o li antes de vir para a aula e às vezes faço pesquisas complementares. Discute-se sobre os diferentes pontos e, no final, o professor resume nossas observações e questões no quadro (SÉVERINE, História, 2007).

b) A percepção mitigada refere-se aos estudantes que insistem simultaneamente sobre os aspectos positivos e negativos: "Na faculdade os professores vêm, dão seus cursos e depois, eu penso, eles pouco se preocupam. As disciplinas são interessantes, mas não há acompanhamento" (CLÉMENT, Administração Econômica e Social, 2006).

c) A percepção negativa, quando os estudantes têm muitas críticas e dão uma opinião global negativa:

A faculdade não é o que eu imaginava! Aqui, os professores são pagos para não fazer nada, dão as disciplinas e é tudo. Em todo caso, eu não tive sucesso neste sistema. Minhas relações são tumultuadas com uma professora; se você preferir é por causa dela que eu fui reprovada (LAURA, Direito, 2008). 
A relação com o aprender na universidade e o meio ambiente de estudos

\section{Perspectiva de aprendizagem \\ Segundo a percepção geral do meio ambiente de estudo}

\begin{tabular}{|l|c|c|c|}
\hline & $\begin{array}{c}\text { Percepção } \\
\text { entusiástica } \\
(31 \%)\end{array}$ & $\begin{array}{c}\text { Percepção } \\
\text { mitigada } \\
(47 \%)\end{array}$ & $\begin{array}{c}\text { Percepção } \\
\text { negativa } \\
(22 \%)\end{array}$ \\
\hline Perspectiva compreensiva & +++ & & \\
\hline Perspectiva de desempenho & ++ & + & \\
\hline Perspectiva minimalista & + & + & + \\
\hline Perspectiva de desengajamento & & + & +++ \\
\hline
\end{tabular}

Como o quadro anterior ilustra, o estudante tendo uma percepção entusiástica adota comumente uma perspectiva de desempenho ou compreensiva. Inversamente, quando o estudante tem uma percepção negativa, ele tem muito mais chances em adotar uma perspectiva minimalista ou uma perspectiva de desengajamento. Raramente encontrei, em minhas entrevistas, estudantes que desenvolveram uma perspectiva compreensiva com uma percepção negativa do contexto pedagógico.

58 Apesar dessa correlação entre a apreciação do contexto e a perspectiva de aprender, era difícil examinar essa questão de uma maneira reflexiva. Em outras palavras, é possível pensar que os estudantes mais motivados e os mais entusiastas conseguem desenvolver mais facilmente uma cumplicidade com o meio ambiente de estudo ou com o professor. Essa hipótese não parece colocar em dúvida a correspondência detectada entre a apreciação do contexto e a perspectiva desenvolvida pelo estudante, mas convida a se ter mais prudência com a análise. A pertinência dessa análise baseia-se mais sobre a ideia que os estudantes tenham mudado sua perspectiva graças ao contexto de estudos. Para certos estudantes, o contexto pedagógico contribuiu para melhorar sua perspectiva.

A pesquisa mostra que um contexto inapropriado ou mal percebido contribui para reduzir o trabalho acadêmico dos estudantes. Ao inverso, encontrei estudantes "instáveis" que conseguiram desenvolver uma perspectiva compreensiva ou de desempenho graças a disciplinas e um contexto pedagógico que eram estimulantes. Alguns estudantes dizem ter descoberto sua área de formação graças ao contexto de estudos, à mediação pedagógica e à boa relação com determinados professores. A dependência dos estudantes ao 
contexto de aprendizagem parece ser variável de acordo com seus traços pessoais. Cada estudante aborda o meio ambiente de estudo com sua biografia e sua experiência. E, entrando em interação com outros parceiros, encontra as condições materiais, organizacionais e interpessoais. Os estudantes mais frágeis, ou aqueles que supervalorizam a dimensão emocional de sua experiência, têm tendência a depender mais do contexto. Então, esses estudantes são mais susceptíveis a se desmobilizar em um contexto percebido negativamente.

julgamento do estudante sobre o seu meio ambiente de estudo constrói-se através de um processo social de uma intersubjetividade situada. Outra dimensão desse processo refere-se ao nível intrasubjetivo ou à percepção avaliativa desenvolvida por cada estudante em interação com o seu meio ambiente de estudo. Esse julgamento contribui para avaliar o meio ambiente de estudo, o contexto humano e pedagógico de sua área de formação. As atividades propostas e a implicação pessoal de cada estudante e suas relações e múltiplas trocas, no seio da comunidade universitária, desenvolvem sua percepção avaliativa. É lógico que nem todos os estudantes dependem da mesma maneira do meio ambiente de estudo. Os mais motivados não se desmobilizam facilmente. Outras investigações mostram bem que os estudantes "frágeis" (percurso anterior menos sólido, escolha universitária incerta, condições de vida difíceis) parecem mais dependentes do funcionamento do meio ambiente de estudo (PAIVANDI, 2010 ). Eles se "desencorajam" mais facilmente, desenvolvendo uma percepção "negativa", marginalizando-se ou excluindo-se.

\section{Conclusão}

As pesquisas sociológicas sobre o percurso ou sobre o desempenho universitário se interessam comumente por dois tipos de variáveis e fatores: as variáveis "externas" referentes à origem social do estudante, seu percurso escolar anterior ou suas condições de vida; e, as variáveis "internas" ao contexto pedagógico e institucional da área de formação como a organização pedagógica, as interações ou ainda a experiência estudantil e sua avaliação subjetiva do contexto pedagógico. A interdependência ou a autonomia relativa dessas duas variáveis é objeto de muitos debates e análises.

A investigação permitiu que se examinassem nas dimensões temporais as trajetórias sociais não determinadas previamente. $\bigcirc$ método longitudinal 
foi o revelador da lógica aprendendo-aprender e sua refletividade através dos momentos decisivos de um percurso e de dinâmicas que, em um momento do percurso de vida, dão sentido a uma trajetória individual. Constata-se que o presente não é apenas tributário do passado e que ele se mostra com desafios que the são próprios. A análise dos dados revelou igualmente a influência do contexto disciplinar e pedagógico sobre as condutas adotadas pelos estudantes. Cada área de formação oferece aos seus estudantes os lugares coletivos de vida, constituindo uma trama, tanto prática quanto existencial, indispensável para a aprendizagem de uma cultura comum.

Assim, uma dimensão importante da socialização estudantil refere-se ao processo intrapessoal, isto é, a avaliação subjetiva e pessoal desenvolvida pelo estudante quanto à universidade e seu contexto. A imagem que o estudante tem de sua instituição lestabelecimento, departamento, área de formação, cursol pode exercer influência sobre suas atitudes e práticas. $\bigcirc$ meio ambiente de estudo, o lugar destinado ao estudante e seu status efetivo no interior do grupo de aprendentes influenciam a tomada de consciência de si no quadro das atividades universitárias. Um contexto pedagógico e social mal apreciado contribui para justificar a desmobilização, a ausência de aprendizagem, o fra60 casso escolar, um investimento acadêmico minimalista ou insuficiente.

Cada estudante aborda seu meio ambiente de estudo através de um processo interpretativo, permitindo-the identificar de uma maneira individual ou coletiva as pistas de ação possíveis. As interpretações conduzem os estudantes a dar um sentido às normas e às práticas propostas pelo contexto universitário. A eficácia e a pertinência desse contexto devem ser percebidas como tais pelos próprios estudantes. A percepção do estudante é um vetor poderoso de seu engajamento e de sua mobilização, constituindo a mediação entre o contexto e a perspectiva de aprendizagem que possa ser desenvolvida, tornando-se também um sentido importante de sua mobilização.

\section{Referências}

ABRAM, David. The spell of the sensuous: perception and language in a more-thanhuman world. New York: Vintage, 1996.

ALAVA, Séraphin; ROMAINVILLE, Marc. Les pratiques d'étude, entre socialisation et cognition. Revue française de pédagogie, Lyon (França), n. 136, p. 159-180, juil./sept. 2001. 
ARUM, Richard; ROKSA, Josipa. Academically Adrift: limited learning on College Campuses. Chicago: University of Chicago Press, 2010.

ASTIN, Alexander. Achieving educational excellence: A critical assessment of priorities and practice in higher education. San Francisco: Jossey-Bass, 1985.

BECKER, Howard Saul; GEER, Blanche; HUGHES, Everett Cherrington; STRAUSS, Anselm. Boys in white: student culture in Medical School. Chicago: University of Chicago Press, 1961.

BIGGS, John. Teaching design for learning. Keynote discussion paper presented at the Annual Conference of the Higher Education Research and Development Society of Australasia (HERDSA). Brisbane, 1990.

BIGGS, John. Student approaches to Learning and Studing. Melbourne, Australian Council for Educational Research, 1987.

BLOOMER, Martin; E HODKINSON, Phil. Learning Careers: continuity and change in young people's dispositions to learning. British Educational Research Journal, Wales (Reino Unido), v. 26, n.5, p. 583 597, may, 2000.

BOEKAERTS, Monique. Motivation, Learning and Instruction. In SMELSER, Neil Joseph; BALTES, Paul (Eds.). The International Encyclopedia of the Social and Behavioral Sciences. Oxford: Elsevier, 2001 . p. $1012-1017$.

BOURDIEU, Pierre; PASSERON, Jean-Claude. Les héritiers. Les étudiants et la culture. Paris: Les Éditions de Minuit, 1964.

COULON, Alain. Le métier d'étudiant. L'entrée dans la vie universitaire. Paris, PUF, 1997.

ENTWISTLE, Nöel. Improving Teaching Through Research on Student Learning. In FOREST, John (Ed.) University Teaching. International Perspectives. New York: London: Garland Publishing, 1998.p. 73-112.

ENTWISTLE, Nöel; ENTWISTLE, Abigail. Revision and the experience of understanding, in MARTON, Ference; HOUNSELL, Dai; ENTWISTLE, Nöel (Eds.). The Experience of Learning. 2. ed. Edinburgh: Scottish Academic Press, 1997. p. 145-158.

FOREST, James (Ed.). University Teaching. International Perspectives. New York: London: Garland Publishing, 1998.

FRENAY, Mariane, NOËL, Bernardette, PARMANTIER, Philippe, ROMAINVILLE, Marc. L'étudiant-apprenant. Grilles de lecture pour l'enseignement universitaire. Bruxelles: De Boeck e Larcier, 1998. 
A relação com o aprender na universidade e o meio ambiente de estudos

GARRISON, Randy, ANDREWS, Jac; MAGNUSSON, Kris. Approaches to teaching and learning in higher education. New Currents, Calgary (Canadá) v. 2, n. 1, jan. 1995. Disponível em: <http://www.ucalgary.ca/pubs/Newsletters/Currents/Vol2.1/approaches.html>Acesso em: 25 abr. 2012.

HERMET, Isabelle. Engagement dans la recherche et rapport du sujet au savoir à l'Université. Genèse du choix de l'histoire et des mathématiques. 2000. 264f. Tese (Doutorado em Psicologia) - Programa de Pós Graduação em Educação, Université Toulouse-Le Mirail, Lille, 2000 .

HICKEY, Daniel. Motivation and contemporary socio-constructivist instructional perspectives. Educational Psychologist, Piscataway (NJ, Estados Unidos) v. 32, n. 3, p. 175-193, juil./ sept., 1997.

JÄRVELA, Sanna; JÄRVENOJA, Hanna; VEERMANS, Marjaana. Understanding dynamics of motivation in socially shared learning. International Journal of Educational Research, Adelaide (Austrália), n. 47, p. 122-135, 2008.

LIGHT, Greg; COX, Roy. Learning and teaching in higher education. The reflective professional. London: Paul Chapman Publishing, 2001.

62 MANN, Sarah. Study, power and the University. Buckingham, SRHE, Open University Press, 2008.

MARTIN, Elaine. Changing Academic Work. Developing the Learning University. Buckingham: SRHE-Open University Press, 1999.

MARTON, Ference; SÄLJÖ, Roger. Approche to Learning. In: MARTON, Ference; HOUNSELL, Dai; ENTWISTLE, Noel (Eds.). The Experience of Learning: Implications for Teaching and Studying in Higher Education. Edinburgh: Scottish Academic Press, 1997.p. 39-58.

MARTON, Ference; DALL'ALBA, Gloria; BEATY, Elizabeth.Conceptions of learning. International Journal of Educational Research, (Adelaide, Austrália)n. 19, p. 277-299, (trimestral) Oct./Dec., 1993.

MARTON, Ference; SÄLJÖ, Roger.On qualitative differences in learning: 1-Outcomes and process. British Journal of Educational Psychology, Wales (Reino Unido), n. 46, p. 4-1 1, apr./june, 1976.

McCASLIN, Mary; HICKEY, Daniel. Educational psychology: Social constructivism and educational practice: A case of emergent identity. Educational Psychologist, Piscataway (Estados Unidos),v. 36, n. 2, p. 133-140, april/june, 2001. 
MEAD, George Herbert Mead. Mind, self and society: from the standpoint of a social behaviorist. [1934] Chicago: The University of Chicago Press, 2005.

MERLE, Pierre. Le rapport des étudiants à leurs études: enquête sur trois populations scolarisées dans des filières «fermées» et "ouvertes». L'Orientation scolaire et professionnelle, Paris (França),v. 26, n. 3, p. 367-387, juil./sept., 1997.

MEYER, Jan; MULLER, Max. Evaluating the quality of Student Learning. Studies in Higher Education, Melbourne (Austrália),v. 15, n. 2, p. 131 1-154, mars/april, 1990.

MILLET, Mathias. Les étudiants et le travail universitaire. Lyon: Presses Universitaires de Lyon, 2003.

PAIVANDI, Saeed. La relation à l'apprendre à l'université. L'enquête sur la perspective d'apprentissage des étudiants de la région parisienne. Recherches sociologiques et anthropologiques, Louvain-la-neuve (Bélgica), v. 50, n. 2, p. 63-75, juil./déc., 2012.

PAIVANDI, Saeed. Le temps studieux des étudiants. In GALLAND, Olivier; VERLEY, Élise (Eds.). Les mondes étudiants. Enquête conditions de vie 2010. Paris: La documentation Française, 2011 .

PERRY, William. Forms of intellectual and ethical development in the college years: a scheme. New York: Holt, Rinehart \& Winston, 1970.

PINTRICH, Paul. A motivational science perspective on the role of student motivation in learning and teaching contexts. Journal of Educational Psychology, Phoenix (Estados Unidos), v. 95, n. 4, p. 667-686, oct./dec., 2003.

RAMSDEN, Paul; ENTWISTLE, Noel. The effects of academic departments on students' approaches to studying. British Journal of Educational Psychology, Wales (Reino Unido),v. 51 , n. 3, 128-148, juil./sept., 1981.

ROMAINVILLE, Marc. Les "Nouveaux" étudiants. In: FRENAY; Mariane; NOËL, Bernardette; PARMANTIER, Philippe; ROMAINVILLE, Marc (Ed.). L'étudiant-apprenant. Grilles de lecture pour l'enseignement universitaire. Bruxelles: De Boeck \& Larcier, 1998.

SÄLJÖ, Roger. Learning in the learner's perspective. Some common-sense conceptions. Report from the Department of Education, University of Göteborg, n. 76, 1979.

SCHUTZ, Albert. The phenomenology of the social world. [1932] Evanston, IL: Northwestern University Press, 1967. 
SVENSSON, Lennart. Skill in Learning and Organising Knowledge.In MARTON, Ference; HOUNSELL, Dai; ENTWISTLE, Noel. The experience of learning: implications for teaching and studying in Higher Education. Edinburgh: Scottish Academic Press, 1997. p. 59-71.

TINTO, Vincent. Leaving college: rethinking the causes and cures of student attrition. Chicago: University of Chicago Press, 1987.

WEIDMAN, John C. Undergraduate socialization. A Conceptual Approach, In: SMART, J. (Ed.) Higher Education Handbook of Theory and Research. New York: Agathon, 1989.

WEIL, Eric. Essais sur la philosophie, la démocratie et l'éducation. Villeneuve d'Ascq, France: Presses universitaires de Lille, 1993.

WILSON, Keithia, LISSIO, Alf; RAMSDEN, Paul. The development, validation and application of the Course Experience Questionnaire. Studies in Higher Education, Melbourne (Austrália),v. 22, n. 1, p. 33-53, jan./feb. 1997.

ZIMMERMAN, Barry. Models of self-regulated learning and academic achievement. In ZIMMERMAN, Barry; SCHUNK, Dale (Ed.). Self-regulated learning and academic achievement: Theory, research and practice. New York: Springerverlag, 1989.

Prof. Dr. Saeed Paivandi Université de Lorraine | Nancy | França Diretor do Laboratoire des Sciences de l'Education et de laCommunication | LISEC | Lorraine E-mail | saeed.paivandi@univ-lorraine.fr Tradução | Prof. Dr. Adir Luiz Ferreira Universidade Federal do Rio Grande do Norte Departamento de Fundamentos e Políticas da Educação Programa de Pós-Graduação em Educação Grupo de Pesquisa "Escola Contemporânea e Olhar Sociológico"| ECOS E-mail | adirlfer@gmail.com

Recebido 15 abr. 2014 Aceito 8 jul. 2014 